\title{
Blackness as Medium. Body in Contemporary Theatre Practice and Theory
}

\author{
Dorota Sajewska, Dorota Sosnowska
}

Peggy Phelan, in her famous text, 'Ontology of Performance', states: 'Performance cannot be saved, recorded, documented, or otherwise participate in the circulation of representations of representations: once it does so it becomes something other than performance. [...] Performance [...] becomes itself through disappearance.' (PHELAN 1993: 146) At the same time she says that body itself cannot be saved, recorded or documented and that it becomes itself only through unmediated presence that can be experienced by other bodies. The performing body is singular and ephemeral - present and real. She explains: 'In performance, the body is metonymic of self, of character, of voice, of "presence". But in the plenitude of their apparent visibility and availability, the performer actually disappears and represents something else - dance, movement, sound, character, "art”.' (PHELAN 1993: 150) How should this be understood? What is the body on stage if it is not the 'body per se'? The answer given by Phelan is not very satisfying. Performance becomes a metaphysical category with its ephemerality that transcends the mortal body. Becoming itself through disappearance, performance is pure experience, not anchored in any kind of materiality. But looking closer at her text one can see that all the examples she analyses are not classical performances. She chooses artworks that are literally based on the use of different media and different technologies. In the very centre of every work cited by Phelan there is a problem of presence, which becomes questionable and unsure. Cindy Sherman (Film-stills) dresses in various costumes to become an image of the body photographed and hung on the wall. She is herself and not-herself at the same time, touching the classical problem of impossible dualism between the actor and the personage she embodies. Angelika Festa, in the work Untitled Dance (with fish and others) - a key example for Phelan - changes her body to a static figure, while the 'performance' is taking place on screen, where different projections enter into a complicated game with the body and its ability to endure. One screen presents the image, which is delayed in relation to the 'real time' presence of the body. Time is questioned here, so is the presence itself. But it is possible to see, through of the use of technology which becomes a tool of mediation. Unwittingly, 
Phelan (through the examples she uses), is defending the almost opposite thesis to that formulated at the beginning of her essay: performance becomes itself through mediation.

Rebecca Schneider, in her book Performing Remains: Art and War in Times of Theatrical Reenactment, and the famous text 'Performance Remains', has formulated one of the most important critiques of Peggy Phelan's performance definition. She argued that categories of ephemerality and disappearance, limit our understanding of performance and its relation to history. She asked: "[I]f we consider performance as "of" disappearance, if we think of the ephemeral as that which "vanishes", and if we think of performance as the antithesis of "saving", do we limit ourselves to an understanding of performance predetermined by cultural habituation to the patrilineal, west-identified (arguably white-cultural) logic of the Archive?' (SCHNEIDER 2013: 138) Assuming a different point of view - non-Western, marginalised, peripheral or defined by race - we can discover that there is nothing ephemeral in performance. Like its ancestor ritual - performance is a medium of memory that transfers and actualizes in the body that official and institutionalised archives reject. The memory that exists outside a text, document, or tangible trace, finds its residue in the body, action, and theatre. Body-to-body gestures are some of the most important media of history, a way to maintain identity. Schneider states: "This is not to say that we have reached the "end of history", neither is it to say that to access the past is impossible. It is rather to resituate the site of any knowing of history as body-to-body transmission.' (SCHNEIDER 2013: 145)

In effect, the only way to overcome the ephemerality discourse is to establish the unresolved tension between body and archive, between performance and written history, between theatrical re-enactment and properly stored documents. This way of thinking is also characteristic of Diana Taylor and her 'archive' and 'repertoire' categories on the one hand (TAYLOR 2003) and for José Muñoz with his 'ephemera' on the other (MUÑOZ 2011). In all of these examples the body becomes a site of history, of a living past that haunts every moment felt as present. This kind of presence that is always anchored in the time, being its own past and future at the same time, can be described as body-archive.

Body-archive means every material documentation of the past treated as having agency: bones, organic remains, objects and places, remains of the past given to technological reproduction and archived as testimonies of what happened 'there and then' by those who live now and those who lived then, as well as records in the literature, audial and visual art and theatre. Body-archive is not only a set of matter that can be experienced in the space of the specially prepared institution, gathering and classifying its collection. It means also every remain of history becoming alive in social and artistic performances with use of different media and source data circulating in the free and fragmentary Internet circuit. (SAJEWSKA 2016)

Body-archive means a kind of presence that renounces the presence itself. It changes into constant re-enactment, repetition, return without limits. The ephemerality of the performance, its tendency to disappear, is then be replaced by its unrefusable connec- 
tion to history coming along with questions about identity, tradition and community. Performance is no longer based on presence and experience. It becomes mediated by the body that is an archive - a site of constant repetition, impossible to establish as being present.

Moving from performance theory to theatre theory, we find a similar concept. In one of the most important books about theatre theory, Samuel Weber states that theatricality, as the oldest form of dealing with the problem of the body and its presence, should be understood literally as a medium. The author - looking at theatricality in its media dimension that enhances the status of being in between, the functioning that escapes any certainty, any permanent nature or unifying approach - views the concept that originates from the theatrical practice as an alternative to the Western philosophical thought, which is perceived as totalising, building permanent identities, excluding otherness, and founded on the metaphysics of presence. Weber, in the footsteps of Plato, finds a subversive power in the theatre that is capable of undermining the Western desire to survey reality with a single, common and integrative view. This potential is also the reason why - from antiquity until the present day (as exemplified by Debord) - the theatre is occasionally presented as a destructive activity whose product is a show that beguiles and obscures the truth. For Weber, on the other hand, it is this mediation between concealment and revelation, truth and fiction, a feature so much depreciated by the Western thought, that is the unique lesson we can learn from the theatre. This specific art practice - in contrast to the classical understanding of a work of art - can never be ultimately defined for being in a state of constant circulation between production and reception. It is this movement that takes place not only - as so far perceived by performance studies - between an actor and a spectator, the body and the participant in the performance, but between the corporeal and the fictitious, the concurrent being here and there, the movement that stretches one's presence between the past, present, and a harbinger of the future, destroys cohesion, unity, and coherence. It is a heterogeneous medium. The theatre is not a means of presenting of an identity, or self-presence, but a condition that must be fulfilled and, as Weber puts it, 'must take place' so as to arrange the given space and place. It is a location determined by the place. And since this perspective, as determined by the place, is by design entangled in artificiality, it induces us with the propensity for taking falsehood for reality; whilst instantly raising suspicion, it reminds us of the relativity of the place we occupy. Theatricality as a medium challenges all the systems.

In the chapter titled 'Scene and Screen: Electronic Media and Theatricality' Weber states that:

One of the traits that distinguishes electricity as a source of energy, at least insofar as it pertains to the electronic media, is its tendency, by virtue of its velocity, to transform traditional experiences of space and time, of distance and proximity, and hence of bodies, which in great part are defined through their spatio-temporal mode of being situated. What would seem to be specific to theater, by contrast, and presumably also to theatricality, as both are traditionally construed, is their dependence upon the 'Euclidean' experience of space-time that the 
electronic media tend to relativize if not to abolish: above all, recourse to the opposition between presence and absence as well as to that of proximity and distance in the situating of bodies, especially living bodies. (WEBER 2004: 99)

Doesn't that mean that the body is no more present than any other medium used in theatrical performance? In the perspective of Weber's concept, not only does theatricality become a medium, but the body itself - oppressed or emancipated by technology, depending on the stand we want to take - becomes a medium between presence and disappearance, between materiality and ephemerality, between reality and fiction.

This is the point of departure for contemporary theatre and its multimedia strategies. But in this essay we ask: what happens when the body on stage is a body of the other? Will it gain any presence? Is it possible to establish a stage presence not anchored in metaphysics?

\section{Black Choir}

In 2014, young theatre director Radosław Rychcik received one of the most prestigious cultural prizes in Poland for his theatrical realization of Adam Mickiewicz's Dziady. This fundamental play for Polish national identity, written between 1822-1860, when Poland was under partitions and didn't exist on the map, is a romantic, phantasmatic vision of Poland which is seen as a metaphysical space where the freedom of the whole universe is fought for. In Rychick's reading, this XIX-century text is, once again (as it was one of the most important drama for Polish theatre of the 1960s and 1970s), actualized and shown as an important statement about contemporary world.

The climax of Mickiewicz's dramatic output is The Great Improvisation - an extreme expression of individualism, a manifestation of the revolt against God in defence of subjective truth regarding faith, freedom and love. In Rychick's spectacle, The Great Improvisation, the greatest text in Polish tradition to be told from the stage; it is presented on screen. This is the scene from the movie by Tadeusz Konwicki in which The Great Improvisation is told by a legendary actor - Gustaw Holoubek who played in Dzi$a d y$ in 1967. That spectatle was banned by the government and is considered to be the beginning of large student protests in 1968 Poland. Rychick's work becomes a kind of monument, a ruin of past theatre and national history which cannot be embodied once again, and haunts from the screen as a powerful ghost of our identity. We hear only the voice of an actor, then already dead, and we look at an unlit stage - a black box. Here, blackness becomes the synonym of theatricality. Maybe that is why it is so easy to pass from Great Improvisation to Martin Luther's King's speech 'I had a dream' in the next scene. Blackness, deprived of any reference in Polish society, is constructed here by pure theatricality - the blackness of the theatre stage. This way, the Polish emancipation movement becomes the African-American emancipation movement. Polish history changes into the history of blackness. Before the actor starts to speak, naked black and white actors slowly surround him. They gather and they become a choir of slaves. 
Moved by the speech, they start to sing about revenge in a melody reminding of an old gospel song. They move from one foot to another. As a crowd they are powerful, beautiful and dangerous. The audience feels their power, which is coming from their bodily presence, the unmediated - in contrast to the projection we've just seen - contact with multiplied singing and moving black bodies. The scene ends with the sound of rain, which becomes a symbol of freedom.

What is striking is the real provenance of blackness - transposed as a notion of slavery and emancipation to the white bodies - on the stage of Polish national drama. In Rychick's Dziady, a certain paradox of absence is revealed: a black body becomes present in a society and country where there are no black bodies, where there is no history and no memory of their suffering and emancipation. They are only mediated to the culture by images, films, photos and literature. But paradoxically, it is by this mediation of black bodies that the emancipatory potential for white bodies - immersed in the history, suffering and memory of their fallen - is born. How should we understand the paradox: that the moment of real presence is, at the same time, a moment of a meaningful lacking? To answer this question, we show how this blackness appearing on the Polish stage, as a function of a theatrical black box, could be understood in the context of blackness as nothingness - one of the most important philosophical readings of blackness by Fred Moten.

\section{Nothingness}

In 'Blackness as Nothingness', Moten states that blackness, understood as nothingness, can be treated as a different form of subjectivity. He writes: '[...] blackness is nothing, that is, the relative nothingness of the impossible, pathological subject and his fellows.' (MOTEN 2013: 741) But at the same time he is not an Afro-pessimist. He doesn't perceive this nothingness in the context of social death and permanent exclusion of black people. 'Is it possible to desire the something other than transcendental subjectivity that is called nothing? What if blackness is the name that has been given to the social field and social life of an illicit alternative capacity to desire? Basically, that is precisely what I think blackness is.' (MOTEN 2013: 778) For Moten, an Afro-optimist, blackness becomes a field of philosophical discourse with universalistic ambitions. He wants to adore and love blackness as a possibility of difference, of being always outside, in a different place. The black subject is not really a subject - it is radically different from always desiring something that is not there, but at the same time is reachable and possible - at hand's reach.

Moten's gesture is very important as he opens the category of blackness to philosophical speculation. At the same time, making it autonomous from the actual body and it's race. His blackness is fluid, unstable, changing and inviting. But at the same time a black body becomes precarious. It is hidden inside his thought as historical reality of suffering, as unreachable fact, as a mute presence that cannot be forgotten nor neglected. He writes: 'Her name is Hortense. Her name is NourbeSe. Her name is B. 
The black chant she hears is old and new to her. She is unmoored. She is ungendered. Her mother is lost. Exhausted, exhaustive maternity is her pedagogical imperative: consent not to be a single being.' (MOTEN 2013: 745) The body he hides behind his philosophy is a body-archive: an actual site of history, where history is ongoing, repeating itself, constituting as a reality. In this case it is a reality of race, of the never ending performance of being black. Being optimistic about blackness's nothingness, Moten is pessimistic about the possibility of leaving a chain of repetitions (living history) that is inscribed in the black body itself. Rinaldo Walcott, writing about blackness in Canada, gives a very good formulation to this problem:

Similarly, when I use the term blackness, I mean to signal blackness as a sign, one that carries with it particular histories of resistance and domination. But blackness is also a sign which is never closed and always under contestation. Blackness for me, like black Canadian, allows for a certain kind of malleability and open-endedness which means that questions of blackness far exceed the categories of the biological and the ethnic. I deploy blackness as a discourse, but that discourse is embedded in a history or a set of histories which are messy and contested. The essays that follow demonstrate how various kinds of blackness are always in progress, always in the process of becoming... (WALCOTT 2003: 27-8)

But what happens if blackness is used as a sign in a society where the black body has not existed in the history of that society? Where blackness cannot be anchored in the body-archive?

In Rychcik's work, black bodies enter the stage not from history but with the Joker, NBA players and Marilyn Monroe, from the pop-culture, which becomes a site of making blackness present as a sign of 'particular histories of resistance and domination'. A medium of pop-culture in theatre becomes an old television set which is almost always present on stage. It shows some hypnotic images, fragments of Lost Highway by David Lynch, some kind of control screen making our status as an audience deeply unsure. Isn't this looped highway, which in Žižek's reading is the psychoanalytic scene of phantasms more real than what we see on stage? Or maybe the stage is only the function of the television screen and it absorbs all its two dimensional characters mixing and re-mixing them in this strange constellation, which is supposed to be the image of our history? And if the television is really a frame for the whole story, how does it influence the status of naked white and black bodies, which are present and live in their confrontation with the ghostly screen?

We argue that this television mode is in fact a space of discourse and meanings. In Rychcik's work, the screen represents a phantasmatic scene of Polishness - with all its history, tradition and archive. Black bodies singing a song of revenge manage to break the discourse and to reach a moment of presence. But this presence is possible only when we stop ourselves from trying to give it any meaning. Blackness on the Polish scene becomes a way to beat the body-archive, to break the discourse that always puts body in the flow of history, to reach the deeply performative moment when body is only a body - without any meaning beside its corporeality. Same moment we start to build an interpretation, to 
read this scene as a statement of similarity between Polish and Afro-American emancipation movement, we lose the presence, we lose the bodies and their performative power. We lose the presence, we lose the bodies and their performative power. This is in fact, a strong political statement. The black body is used here to build a new kind of bodily presence on stage. It is only possible to reach this presence if the stage body does not reflect any historical and social meaning. If it breaks the chain of repetition, becomes nothingness - a new mode of being. This political dimension of blackness on the Polish stage is even more visible in other works by young Polish artists.

\section{Black Island}

Krzysztof Garbaczewski's and Marcin Cecko's 2011 play, The Sexual Life of Savages, is the first instance in which famous Polish-British anthropologist Bronisław Malinowski's legendary work by the same name, along with his A Diary in the Strict Sense of the Term, were adapted for the stage. It is an attempt to explore the body confronted with new technologies, as well as with post-anthropocentric discourse. It does so in order to pose a question on the status of the savage-body in contemporary mass media culture and, simultaneously, to undertake a critical review of temporality and history. 'Savages. There was such a tribe. I remember. I used to be a part of it.' ${ }^{1}$ - these words set in motion the exploration of the memory of the Other as a part of oneself. For this purpose, Garbaczewski and Cecko cast a group of young uncompromising actors who, as in their private lives, formed a kind of artistic tribe in a laboratory of sorts, the post-industrial space of an old printing house - Dom Słowa Polskiego - in Warsaw. Its labyrinthine architecture - while being incredibly suggestive on account of its overwhelming sense of entropy, decay and energy loss - is ruthless and uncomfortable for the actors as it is for the spectators. This very performative setting, emanating a sense of emptiness that is impossible to fill and resembling some kind of cellar, thanks to the dim light given off by the low-hanging lamps, proves to be the ideal space for studying the memory of a futuristic Savage tribe, discovering their own primality through the radical use of network technology. The faintly seen and heard actors move about like shadows in the monotonous, hypnotic rhythm of the action; often, they only allow themselves to be definitively discerned and located through the use of media and projection screens. They challenge the myth of theatre as being based on 'live experience' as well as the myth of new media understood as 'non-living technology'.

The humanity represented in Garbaczewski's and Cecko's play, or rather acted out by the modern Savages, falls outside of the scale differentiating man from animal and man from machine. Here, nature does not exist without technology, nor hyperconsciousness without instinct. Studying the ontological status of savages is, however, not an abstract pursuit, but one entrenched in history. 'History as fur means a lot', the character Outsider is told by Aria, a mutant inhabiting a video-projection cave. 'With time, your hair

1 All quotations of the play are taken from the unpublished screenplay, provided by Nowy Teatr in Warsaw. 
grows, becomes thicker. It all comes from knowledge, which you place on this gelatinous mass right here. Through experience forming the shapes underneath the fur.' The land of the Savages, therefore, exhibits a temporal dimension as well as a historical one - it is a grey zone, a settlement of 'civilisational fugitives' who deliberately isolate themselves from economic structures based on production and reproduction. The Savages, critical of modern civilisation and in opposition to the values promoted by the capitalist system, yearn to recover the remains of the kula ritual - their only pursuit is contemplation and free exchange, including offering up their bodies and themselves, oblivious to the concept of ownership. They take from others and share what is their own, creating a non-total unity - 'a network of entangled senses, tender, lazy bodies, minds hungry for stimulation'.

This tribe of human copies, animalistic mutants, technological beings thus undermines Malinowski's extremely rationalistic, biologically-based stance as a researcher on sexuality. In Garbaczewski’s and Cecko's play, this 'ignorance of paternity' that Malinowski treats as a primitive mental state is replaced with a level of technological advancement in which reproduction may occur independently of biology. Here, animism takes the form of techno-animatism, where spirits, memories and the past could be made to return with the use of technology, cloning, and the network-structured reality.

'We can never be sure what our leased bodies will do. And we're left only with lingering traces, disappearing imprints', says one of the play's characters, suggesting that physiological processes are inseparable from the spirit world, and life from death. In Garbaczewski's and Cecko's play, this speculative undercurrent was expressed in a literal fashion, but also philosophically in the set design produced by the visual artist and architect Aleksandra Wasilkowska, who created an autonomous installation - the Black Island, modelled after a map of Papua New Guinea from the year 1600, which Bronisław Malinowski describes in The Sexual Life of Savages. The enormous Black Island has a unique presence in the production: it is a key performer, suspended above the stage and audience, moving throughout the course of the play on the basis of a precise algorithm applied to the movements of the actors and the behaviour of the audience. The fictional territory of the Savages was thus conceived as an inverted island; living, migrating and dominating the entire space, it oversaw the process of constant flow and exchange of energy. Thanks to this 'concept of a meta-mechanical anti-utopia that is the Black Island' undermining the boundary between the 'living bodies' of the audience and cast and the 'lifeless objects in the set', there emerges a certain post-anthropocentric reality dominated by the energy of the earth and territory, as opposed to people and machines. The creator of the installation explained it this way:

The island came about through my fascination with inanimate matter and its ability to self-organise. [...] I am fascinated when I image a future situation in which not machines but territory reigns supreme. The mineral world's rule over human beings. Therefore, I wanted to show that it won't necessarily be man controlling the territory but rather the territory - its fluctuating magnetic fields, the oil and radioactive waste concealed within it, all of the hidden mineral energy - will start to control us. (WASILKOWSKA 2011: 89) 
And so, here, the island rules over the Savages while, at the same time, being a material manifestation of their 'savage' minds. Hovering overhead, the Black Island's presence is oppressive, but, not fitting into the frame of a supervisory glance, it remains, in a way, invisible. It offers critical commentary on the way in which white society still endeavours to control blackness - by feminising the black body, white society objectifies and, in effect dehumanises, blackness. By choosing the Black Island as the only sign of blackness in the spectacle, by denying the inscription of the race into the real body, artists also give a strong statement about the ambivalence of the bodily presence on stage. The technology used by them is then a critical tool, oriented not to emphasise the organic and natural aspects of the 'real' body but to ask about oppressive dimension of 'liveness', 'experience' and 'presence' discourse characteristic to theatre and to anthropology as well.

\section{The Black Body as Medium}

Returning then to the theoretical categories proposed at the beginning of the article, we could say that the two examples show blackness becoming a field of thinking about a new kind of performative body in theatre. This black body is not a body-archive. It is not anchored in history but it becomes a site of theatre theory. It reaches its presence without any metaphysical dimension. It builds meaning without any reference to the live experience - it refers only to multitudes mediations and by the mediality it regains its presence, which has no metaphysical dimension. This is the mediality which constructs the historicity, but this historicity is not a burden anymore - as it was in blackness philosophy. The black body in Poland has its emancipatory power because it is not a body-archive, it doesn't allow the reconstruction of the past, the embodiment of history. In theatre it becomes a pure medium, by placing its presence in constant mediation, without any fixed place or meaning.

At the same time, the close reading of the body status in those two works uncovers many more general questions. To fully understand today's role of the body, which is being transformed by race and technology, a return to questions about presence and experience is essential, along with the expansion of theatre discourse to such categories as an actor's personal body, a body mediated by another medium or his/ her mode, technologically alienated from the whole. Such broader perspective would be approached by the perspective, which we operatively called the meta-media theory of theatre. It postulates, after Weber's concepts, that the theatre is to be considered as a specific medium that critically comments on other media, looks at their editing and sequencing strategies - also incorporates a reflection on the political dimension of annexing media-mediated and media-manipulated corporeality, for it allows to follow the apparently transparent and natural dimension of such actions, whereby once again it turns, as postulated by Jacques Rancière, aesthetic considerations into political considerations. As Weber states: 
[The] irreducible opacity defines the quality of theatre as medium. When an event or series of events takes place without reducing the place it 'takes' to a purely neutral site, then that place reveals itself to be a 'stage,' and those events become theatrical happenings. As the gerund here suggests [...] such happenings never take place once and for all but are on-going. This in turn suggests that they can be neither contained within the place where they unfold nor entirely separated from it. They can be said, then, in a quite literal sense, to come to pass. They take place, which means in a particular place, and yet simultaneously also pass away not simply disappear but happen somewhere else. Out of the dislocations of its repetitions emerges nothing more or less than the singularity of the theatrical event. Such theatrical singularity haunts and taunts the Western dream of self-identity. (WEBER 2004: 7)

The appearance of the Other - understood as a non-western subject, as body, as race, as machine, as animal - challenges that self-identity, unveiling the theatre and stage as a place of constant meditation and repetition, as a shifting space of possible subversion.

\section{Conclusion}

Blackness, along with electronic media and new technologies on stage, is a trigger for great change in the body status. It functions like a deeply critical tool that makes it possible to see and formulate certain ideas that are new to theatre and performance. The body on stage can gain its presence only if it is deprived of history. That is why the theoretical proposition of Weber is so important. Theatricality, as a status of space, time and body is endlessly mediated and shifted, is always not here and not now. It requires a stand to be taken, and a certain point of view (to become a viewer) reveals itself as a political category in much stronger way than performance when it is built on the idea of emancipation by ephemerality and immateriality. The black body on the Polish stage shows new theoretical and emancipatory potential. It is not a body-archive, because it doesn't become a tool for re-enactment, because it denies embodying a history. In theatre it becomes a strongly present medium - its void reference appears on stage as a pure presence, gaining meaning only in constant mediation, constant unfixed movement of meanings. The black body presence shows its performative power. Any attempt to attribute meaning to this body, immediately effaces it, the body disappears. At the same time the body remains intrusively present, if there is no attempt to inscribe it in any chain of references, meanings, traditions or histories. The black body is a signifié and signifiant, mediation and medium. This way, on the Polish stage, a mechanism of theatricality appears. Theatre presents itself as a communication machine, which makes a void reference meaningful. Mediation becomes communication. 


\section{Bibliography}

MOTEN, Fred. 2013. Blackness and Nothingness (Mysticism in the Flesh). The South Atlantic Quarterly 112 (2013): 4: 737-80.

MUÑOZ, José Esteban. 1996. Ephemera as Evidence. Women and Performance: a journal of feminist theory 8 (1996): 2: 5-16.

PHELAN, Peggy. 1993. Unmarked: The Politics of Performance. New York: Routledge, 1993.

SAJEWSKA, Dorota. 2016. Nekroperformans. Kulturowa rekonstrukcja teatru Wielkiej Wojny. Instytut Teatralny im. Z. Raszewskiego, Warszawa 2016.

SCHNEIDER, Rebecca. 2011. Performing Remains. Art and war in times of theatrical reenactment, London/New York, NY: Routledge, 2011.

SCHNEIDER, Rebecca. 2013. Performance Remains. In Perform, Repeat, Record. Live Art in History. Amelia Jones and Adrian Heathfiled (eds.). Bristol/Chicago: intellect, 2013.

TAYLOR, Diana. 2003. The Archive and The Repertoire. Performing Cultural Memory in The Americas. Duke University Press, 2003.

WALLCOT, Rinaldo. 2003. Black like Who? Writing Black Canada. Toronto: Insomniac Press, 2003.

WASILKOWSKA, Aleksandra. 2011. Tworzenie ryzyka [Risk Creation] interview by Jakub Papuczys. Didaskalia (2011): 103: 89-92.

WEBER, Samuel. 2004. Theatricality as Medium. New York: Fordham University Press, 2004. 


\section{Summary}

\section{Blackness as Medium. Body in Contemporary Theatre Practice and Theory}

Our text presents the theoretical approach to the problems of body and technology in stage performance. The starting point is the status of the categories such as presence, ephemerality, immediacy of the (theatre) performance, radically undermined in the texts of performance studies scholars such as Rebecca Schneider, Amelia Jones or Philip Auslander. Utilizing examples of performances from young Polish theatre: Krzysztof Garbaczewski (b. 1983) and Radosław Rychcik (b. 1981), we juxtapose two functioning models of the body-technology relation on stage. The first - represented by Garbaczewski - is based on an understanding of the body as always mediated. It multiplies (undermines) the body's presence by use of audio-visual means. The second - Rychcik's case - is to push the theatrical presence of the body to the absolute maximum. In this case, the audio-visual layer is used to build a strong opposition to the actor's stage presence. The two examples are used to propose a new theoretical approach. We show that such stage phenomena are not only a sign of a (technological) reality shift, but also, a very important theoretical input in the understanding of theatre. We state that every single body on stage (no matter if consciously, as in Garbaczewski's case, or unconsciously as in the Rychcik's case) is already mediated and the use of technological tools is a way to play with this specific character of theatre corporeality. This broader perspective also incorporates elements of the political dimension of annexing media-mediated and media-manipulated corporeality, for it will follow the apparently transparent and natural dimension of such actions, whereby once again it will turn, as postulated by Jacques Rancière, aesthetic considerations into political considerations.

\section{Keywords}

performance theory, Polish theatre, media, body, presence, liveness, mediation

DOI: 10.5817/TY2016-2-5

\section{Dorota Sajewska, Prof. Dr.}

Slavisches Seminar, University of Zurich

E-mail: dorota.sajewska@uzh.ch

Dorota Sajewska is an Assistant Professor for Interart (Osteuropa) at the University of Zurich. She is the author of tree books: 'Chore sztuki'. Choroba/tożsamość/dramat ['Sick plays'. Illness/identity/drama] (2005), Pod okupacja mediów [Under media occupation] (2012) and Nekroperformans. Kulturowa rekonstrukcja teatru Wielkiej Wojny [Necroperformance. Cultural reconstruction oft he theatre of WWI] (2016). Her academic interests are in the area of the relationships between body and archive, performance and history, as well theatre and politics.

Dorota Sosnowska, Ph.D.

Institute of Polish Culture, University of Warsaw

E-mail: d.e.sosnowska@gmail.com

Dorota Sosnowska, Assistant Professor at Theatre and Performance Department at the Institute of Polish Culture, University of Warsaw. She is interested in the area of theatre and performance theory, especially in the context of documentation. 